UDK 621.43 .056

MASOUD HAJIVAND, PhD student of Aircraft engines design Department, National aerospace university named after N.Y. Zhukovsky «KhAI», Kharkov

\title{
CFD MODELING OF KEROSENE COMBUSTION WITH VARIOUS INITIAL CONDITIONS AND FUEL DROPLET DIAMETERS
}

This paper presents the numerical models for the analysis of combustor fuel spray, characteristics, in various injection conditions in a can type of combustor with a double stage radial swirler. Spray consists of two fundamental and consecutive steps, means the primary breakup and the secondary breakup. The primary breakup is modeled by Linearized Instability Sheet Atomization (LISA) which are mostly used in a pressure swirl atomizers. Secondary breakup is modeled by Taylor analogy breakup model (TAB). The trajectory and velocity of generated fuel droplets is determined by Lagrangian Particle Tracking. Characteristics of jet breakup, depends on a variety of factors such as turbulence, injection pressure drop, velocity profiles, nozzle geometry, and the physical state of the liquid fuel. In this paper Jet-A aviation fuel (kerosene), modeled as a two-component surrogate fuel (by mass $60 \% \mathrm{C} 10 \mathrm{H} 22$ and $40 \% \mathrm{C} 9 \mathrm{H} 12$ ). The standard $k-\varepsilon$ model with the enhanced wall treatment and the Euler-Lagrange method were employed for the simulation of the turbulence and spray. All results of the simulation in this paper are analyzing in 3 various injection conditions and one of these cases was chosen and implemented in a real annular combustion chamber of a gas turbine. A PDF Flamelet model was employed to simulate combustion process.

Key words: primary breakup, pressure swirl atomizer, spray combustion

\section{Introduction}

The process of liquid atomization has applications in numerous industrial branches, for example, in chemical, mechanical, aerospace, and civil engineering as well as in material science and technology and metallurgy, food processing, pharmaceuticals, agriculture and forestry, environmental protection, medicine, and others [1] and is essentially one in which bulk fuel is converted into small drops. It represents a disruption of the consolidating influence of surface tension by the action of internal and external forces. In the absence of such disruptive forces, surface tension tends to pull the liquid into the form of a sphere, which has the minimum surface energy. Liquid viscosity has an adverse effect on atomization because it opposes any change in system geometry. On the other hand, aerodynamic forces acting on the liquid surface promote the disruption process by applying an external distorting force to the bulk liquid. Breakup occurs when the magnitude of the disruptive force just exceeds the consolidating surface tension force [2].

The atomization process is generally regarded as comprising two separate processesprimary atomization, in which the fuel stream is broken up into shreds and ligaments, and secondary atomization, in which the large drops and globules produced in primary atomization are further disintegrated into smaller droplets. These processes together determine the detailed characteristics of the fuel spray in regard to droplet velocities and drop-size distributions. In practice, they are markedly affected by the internal geometry of the atomizer, the properties of the gaseous medium into which the fuel stream is discharged, and the physical properties of the fuel itself [2].

Numerical modelling and $C F D$ simulations are an important tool in design and optimization of gas turbine combustion chambers. Advances in computational modelling have resulted in an extensive application of numerical simulations to gas turbine combustors, providing insights and improving the understanding of the combustion process [3]. 
In this paper simulation has been performed using the Computational Fluid Dynamics (CFD) commercial code $A N S Y S C F X$ release 15, with 3 various injection conditions such as injection pressure drop, geometry of fuel nozzles, including primary and secondary breakup model of atomization in a can type of combustor and beside these simulations the prompt and thermal formation of NOx was implemented.

The purpose of this study is to investigate injection and atomization characteristics of liquid kerosene fuel in a pressure swirl atomizer, into a can type combustor. All these investigations and simulations are performed in 3 various cases. The purposes of this study is to compare all the numerical results together, such as, 1 - Mean Diameter of droplets at the initial time of the injection (Time $=0[\mathrm{~s}]$ ). 2 - Effect of injection pressure difference (pressure drop) on primary droplet sizes. 3 - Effect of fuel nozzle geometry on atomization characteristics. 4 - Investigation of NOx formation, in all these 3 various cases. 5 - To choose an appropriate case from our simulation, to implement and perform it, on a real annular gas turbine combustion chamber.

\section{Turbulence and governing equations for fluid modeling}

The standard $k-\varepsilon$ turbulence is applied for the numerical calculation of turbulent twophase flow. The governing equations for the fluid phase are given as:

Continuity:

$$
\frac{\partial a_{g}}{\partial t}+\frac{\partial}{\partial x}\left(a_{g} u_{i}^{g}\right)=0
$$

Momentum equation:

$$
\frac{\partial a_{g} u_{i}^{g}}{\partial t}+u_{j}^{g} \frac{\partial a_{g} u_{i}^{g}}{\partial x_{j}}=-\frac{a_{g}}{\rho_{g}} \frac{\partial p_{g}}{\partial x_{i}}+\frac{\partial}{\partial x_{j}}\left[a_{g}\left(v+v_{T}\right)\left(\frac{\partial u_{i}^{g}}{\partial x_{j}}+\frac{\partial u_{j}^{g}}{\partial x_{i}}\right)\right]+\frac{1}{a_{g} \rho_{g}} M_{p}
$$

Turbulent Kinetic Energy, ( $k$ equation):

$$
\frac{\partial(\rho k)}{\partial t}+\nabla \cdot(\rho U k)=\nabla \cdot\left[\left(\mu+\frac{\mu_{t}}{\sigma_{g}}\right) \nabla k\right]+P_{k}-\rho \varepsilon .
$$

Turbulence Dissipation Rate Equation, ( $\varepsilon$ equation):

$$
\frac{\partial(\rho \varepsilon)}{\partial t}+\nabla \cdot(\rho U \varepsilon)=\nabla \cdot\left[\left(\mu+\frac{\mu_{t}}{\sigma_{g}}\right) \nabla \varepsilon\right]+\frac{\varepsilon}{k}\left(C_{\varepsilon 1} P_{k}-C_{\varepsilon 2} \rho \varepsilon\right) .
$$

\section{Particle tracking model:}

In the analysis of atomization of fuel spray, it is based on particle transport theory of multiphase model and the fuel particle track that is formed by the flow in the point of Lagrangian view is tracked (Lagrangian particle tracking) [4]. Trajectory of liquid droplets is tracked using a two-way coupling with the fluid phase. The scheme is performed by integrating the force balance equations for individual particles (Shi \& Kleinstreuer 2007) [5].

Particle Translation: 


$$
\frac{d \vec{r}_{p}}{d t}=\vec{U}_{p}
$$

Particle momentum:

$$
m_{p} \frac{d \vec{U}_{p}}{d t}=\frac{1}{8} \pi \rho_{p} d_{p}^{2} C_{D}\left(u_{g}-u_{p}\right)\left|u_{g}-u_{p}\right| .
$$

The interphase drag term is determined by Ishii-Zuber (1979) drag model:

$$
C_{D}=\frac{24}{\operatorname{Re}_{m}}\left(1+0.15 \mathrm{Re}_{m}^{0.687}\right) \quad \text { for } \quad \mathrm{Re}<1000 \text {. }
$$

When the droplets are in the viscous regime, the drag coefficient is identical to the Schiller Naumann correlation (Clift, Grace \& Weber 1978) and the shape of droplet is assumed to be spherical. $\mathrm{Re}_{m}$ is the mixture Reynolds number which is defined as:

$$
\operatorname{Re}_{m}=\frac{\rho_{m} d_{p}\left|u_{p}-u_{g}\right|}{\mu_{m}}
$$

In the distorted fluid particle regime, there is increased drag on fluid particles, due to the wake characteristics of turbulent eddies and particle motions. The Drag coefficient becomes:

$$
C_{d}=\frac{4}{3} r_{p} \sqrt{\frac{g \Delta \rho}{\sigma}}\left\{\frac{1+17.67\left[f\left(a_{d}\right)\right]^{6 / 7}}{18.67 f\left(a_{d}\right)}\right\}^{2} .
$$

Where $f\left(a_{d}\right)=\left(1-a_{d}\right)^{1 / 2} \frac{\mu_{g}}{\mu_{m}}$.

An additional correction formula is used to determine the dynamic drag coefficient of deformed droplets (Liu, Mather \& Reitz 1993)

$$
C_{D, \text { droplet }}=C_{d}(1+2.63 y) \quad 0<y<1 .
$$

Where $y=1$ when the particle is maximally distorted.

\section{Liquid Breakup regimes:}

The breakup of a liquid jet (shown in Fig. 1), into droplets is caused by a combination of different mechanisms: turbulence within the liquid phase, implosion of cavitation bubbles and external aerodynamic forces acting on the liquid jet. Depending on the injection parameters such as the relative velocity between liquid and gas, the liquid and gas densities and the liquid viscosity and surface tension the contribution of each of the above mechanisms to the spray breakup varies.

Breakup regimes are typically classified in terms of the dimensionless numbers: Weber Number (We) and Ohnesorge number (Oh), as given by: 


$$
\begin{aligned}
& \mathrm{We}=\frac{\rho_{F} V_{s l i p}^{2} d_{P}}{\sigma}, \\
& \mathrm{Oh}=\frac{\mu}{\sqrt{\rho_{P} \sigma d_{P}}} .
\end{aligned}
$$

Where the subscript $\mathrm{P}$ refers to the droplet (particle) and the subscript $\mathrm{F}$ refers to the surrounding fluid. Sometimes, the Weber number is defined using the particle radius .If a droplet is exposed to a gas flow, significant deformation starts at a Weber number of unity. Above a certain value of the Weber number, the droplet deformation leads to breakup. Typically, the following breakup regimes are observed: [6]

Vibrational Breakup (We $<12$ ).

Bag Breakup $(12<\mathrm{We}<80)$.

Stripping Breakup $(80<\mathrm{We}<350)$.

Catastrophic Breakup (We $>350$ ).

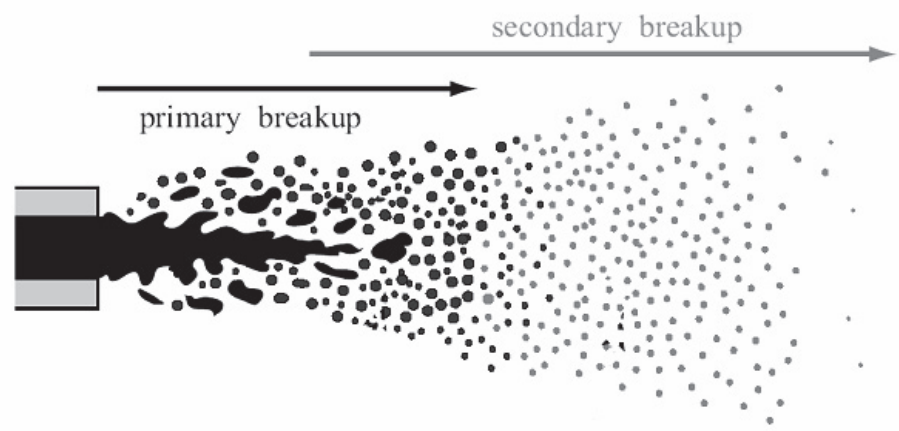

Fig. 1 - Primary and secondary breakup region

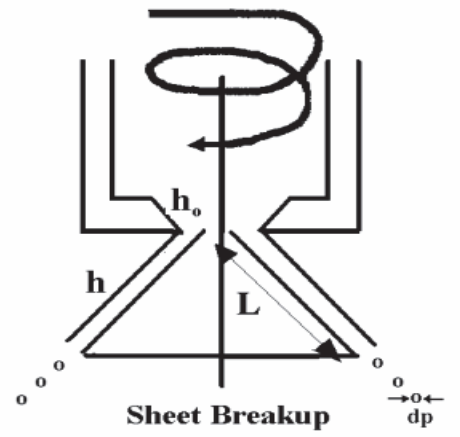

Fig. 2 - Pressure swirl atomizer

\section{Primary breakup model (LISA) model:}

Pressure swirl atomizers (shown in Fig. 2.) are often used in order to establish hollow cone sprays. These sprays are typically characterized by high atomization efficiencies. With pressure swirl injectors, the fuel is set into a rotational motion and the resulting centrifugal forces lead to a formation of a thin liquid film along the injector walls, surrounding an air core at the center of the injector.

Outside the injection nozzle, the tangential motion of the fuel is transformed into a radial component and a liquid sheet is formed. This sheet is subject to aerodynamic instabilities that cause it to break up into ligaments [6].

Secondary breakup model Taylor analogy breakup (TAB) model, (O'Rourke \& Amsden 1987):

The TAB model is based on Taylor's analogy where the droplet distortion is modeled as a damped spring-mass system (shown in Fig. 3.). Droplet viscosity acts as the damping force while surface tension acts as the restoring force. Breakup occurs when the deviation of the particle equator from its equilibrium position becomes larger than half the droplet radius. The radii of the child droplets is determined by an energy balance between the parent and child droplets which results in: 


$$
\frac{r_{P, \text { parent }}}{r_{P, \text { child }}}=\left[1+0.4 K+\frac{\rho_{P} r_{p, \text { parent }}^{3}}{\sigma} \dot{y}_{0}^{2}\left(\frac{6 K-5}{120}\right)\right]
$$

Where $\mathrm{K}$ is the energy ratio factor which attains a value of $10 / 3$ and $\dot{y}_{0}$ is the initial value of the distortion rate of change. For the TAB model, y o is assumed to be zero.

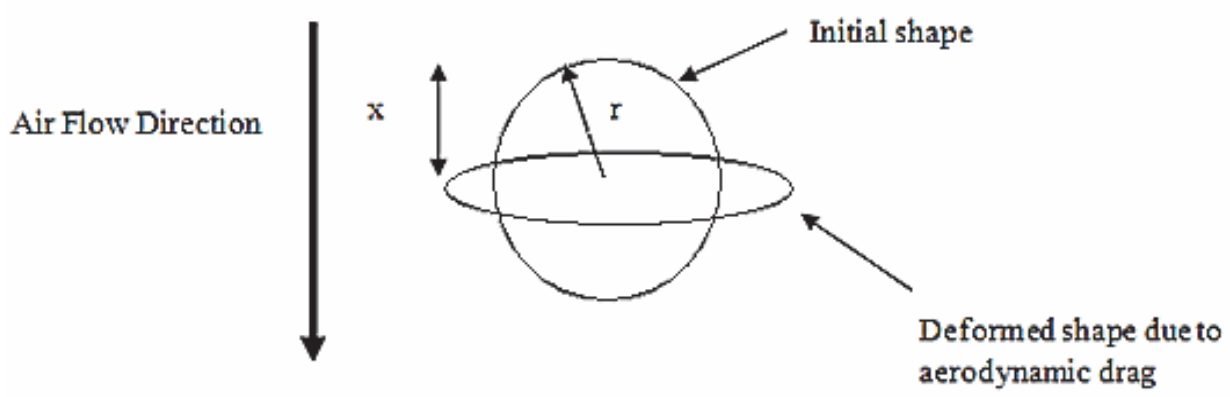

Fig. 3 - Droplet deformation in airflow (particle distortion) (by the TAB model)

\section{Flamelet modeling:}

Non-premixed flames can be used to describe general liquid combustion processes in gas turbines. The problem is simplified to the mixing and reaction of two opposing streams of fuel and oxidizer. The flamelet model employed in this case is based on the assumption that a turbulent diffusion flame appears as a steady, one-dimensional laminar strained flame.

This assumptions holds in many applications for turbulent gas diffusion flames [7-9] A flamelet model gives a compromise between accuracy of results and simulation time for reacting flows and simultaneously incorporates the detailed chemical kinetics for the turbulent combustion simulations. In order to couple the impact of the flow field on the flame structure and shape, the flamelet library is created for two input parameters, the mixture fraction and the so-called scalar dissipation rate. The relation between them is expressed by equation (14).

Within the model the scalar dissipation rate is considered as a parameter that incorporates the convection diffusion effect in the mixture fraction space. The information enclosed in the flamelet library, in the form of look-up tables, incorporates species, density and temperature profiles in the mixture fraction space required for further evaluation of the combustion characteristics and formation of pollutants. A statistical distribution of the mixture fraction and the scalar dissipation in the turbulent flow field is specified by a beta PDF function which provides the information for the mean values of the temperature, density and species mass fractions $[8,9]$.

$$
\chi=2 D|\nabla f|^{2}
$$

Where $D$ is diffusion coefficient and $\mathrm{f}$ is the mixture fraction

The principle of the flamelet generation is expressed by the set of the following partial differential equations (15) and (16) listed below for the species mass fraction and temperature $T$ for a given scalar dissipation rates [8]:

$$
\rho \frac{\partial Y_{i}}{\partial t}=\frac{1}{2} \rho \chi \frac{\partial^{2} Y_{i}}{\partial f^{2}}+S_{i}
$$




$$
\rho \frac{\partial T}{\partial t}=\frac{1}{2} \rho \chi \frac{\partial^{2} T}{\partial f^{2}}-\frac{1}{2} \sum_{i} H_{i} S_{i}+\frac{1}{2 C p} \rho \chi\left[\frac{\partial C p}{\partial f}+\sum_{i} C p, i \frac{\partial Y_{1}}{\partial f}\right] \frac{\partial T}{\partial f} .
$$

NOx formation modeling:

Due to the low NO concentration, the effect of NOx formation process on the flow field is neglected. So the prediction of NO is post processed from the simulation. In this paper, the thermal and prompt mechanisms of NO formation were adopted [10]. For thermal and prompt NOx mechanisms, only the NO species transport equation is needed:

$$
\Delta \cdot\left(\rho \vee Y_{N O}\right)=\nabla \cdot\left(\rho D \nabla Y_{N O}\right)+S_{N O}
$$

Where $Y_{N O}$ is the NO mass fraction, $D$ is the effective diffusion coefficient, $S_{N O}$ is the source term.

\section{Geometrical parameters of can and annular combustion chamber:}

In this investigation the computational domains consist a can type combustor and 20 degree sector of the single annular combustor with single fuel nuzzle and a double stage radial swirler, case and liner without any dilution holes, because in this study we are not going to simulate the combustion processes with primary and secondary dilution holes.

The can combustor consist of 3 section (fig. $4 a$ ): 1 - the area of combustion (burner), which houses the main air swirler and main gas and liquid fuel system; 2 - the area where air enters the burner domain through the radial swirler; 3 - radial swirler (fig. $4 c, d$ ).

For the single annular combustor (fig. $4 b$ ) the main combustion Air enters through a double radial swirler. The swirl number is sufficiently high to induce a vortex breakdown reverse flow zone along the axis .This is termed the internal reverse flow zone. In the concept this reverse flow zone remains attached to the back surface of the combustor, thereby establishing a firm aerodynamics base for flame stabilization, an external reverse flow zone is established. The flame is stabilized in the shear layers around the internal and external reverse flow zone.

\section{Meshing}

Unstructured tetrahedral meshes with prismatic layer were employed for this numerical simulation. Fig. 5 shows the tetrahedral meshes for the can and annular combustors in this study. In order to obtain the maximum resolution of injection, atomization of liquid fuel, Droplet evaporation, we need to create high quality tetrahedral mesh especially around or on the areas which are very important for predicting results and the accuracy of our numerical results. The total grid number for can combustor is 3700000 elements with high quality and prismatic layers near the walls and about 10000000 for single sector annular combustor.

If we plot a typical velocity profile in the near-wall region, we can see that we have a large change in velocity in the wall normal direction and it is important to our $C F D$ simulation that we capture this gradient correctly. To do this, we need to use inflation layer meshing to accurately capture the boundary layer region for any wall-bounded turbulent flows. 

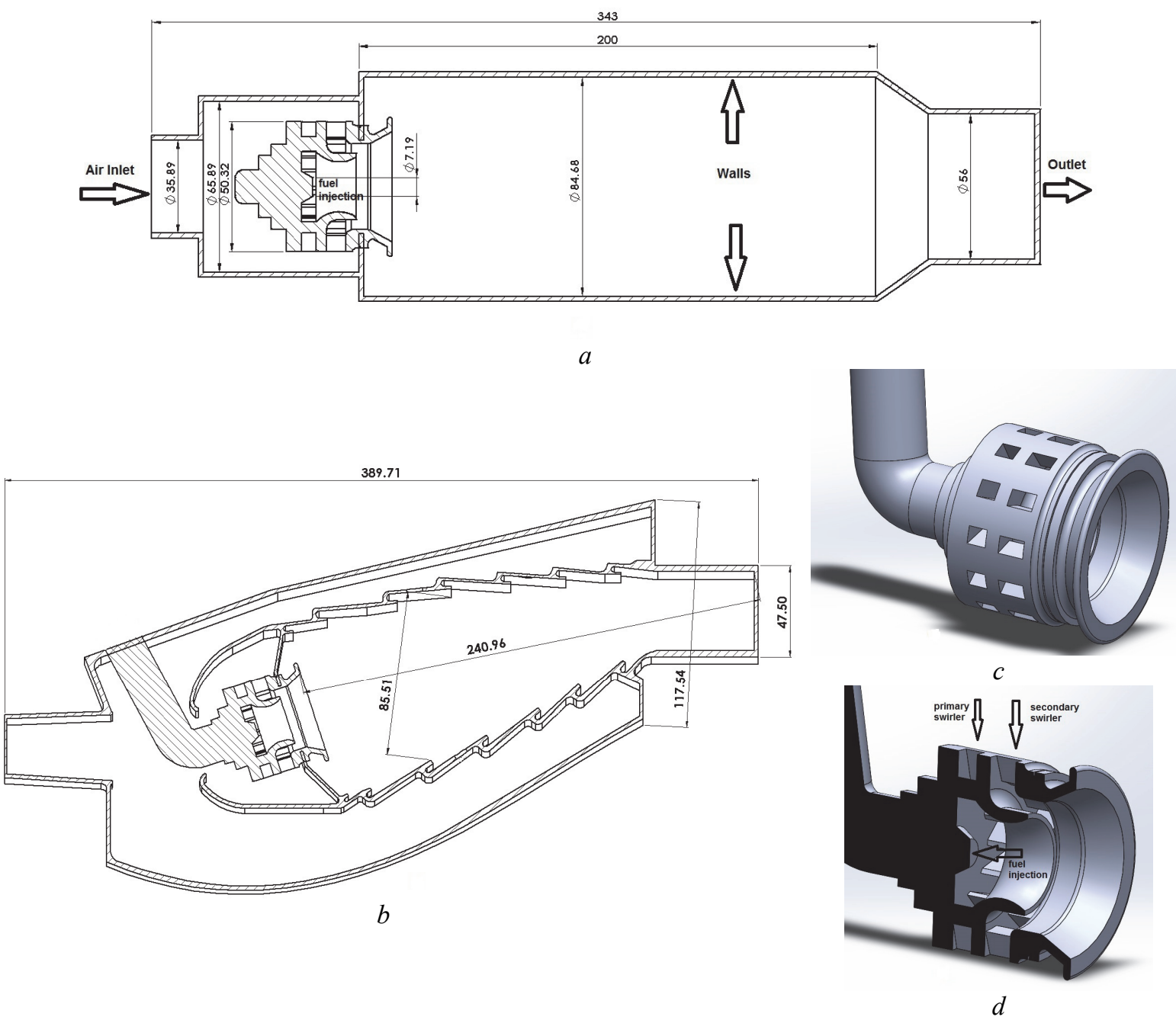

Fig. 4 -3D model of combustors and radial swirler:

$a$ - Can combustor with double stage radial swirler; $b$ - Annular combustion chamber without any primary or secondary dilution holes, with double stage radial swirler; $c$-double stage radial swirler; $d$ - cut-plane of radial swirler

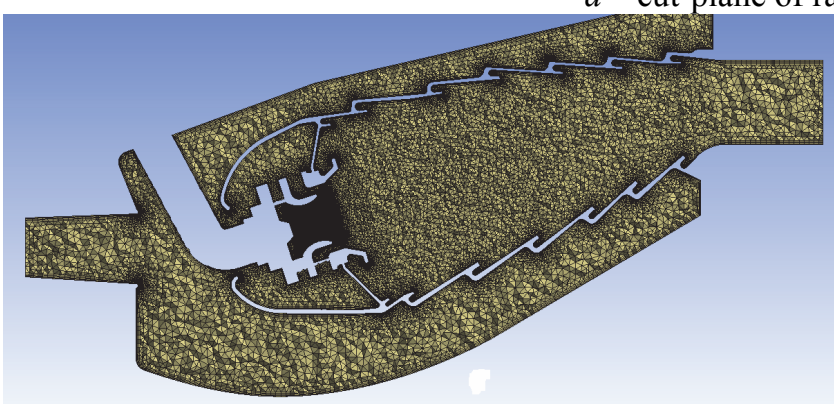

$a$

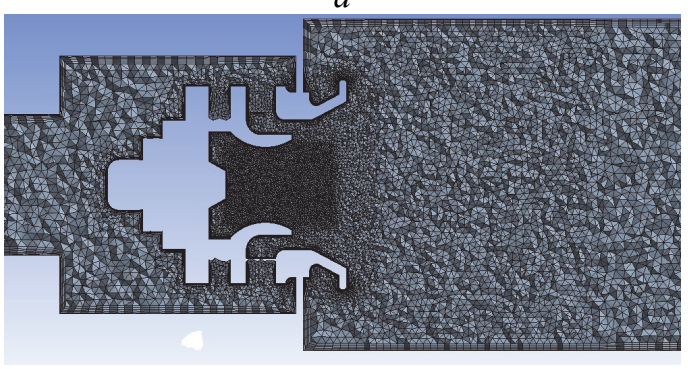

C

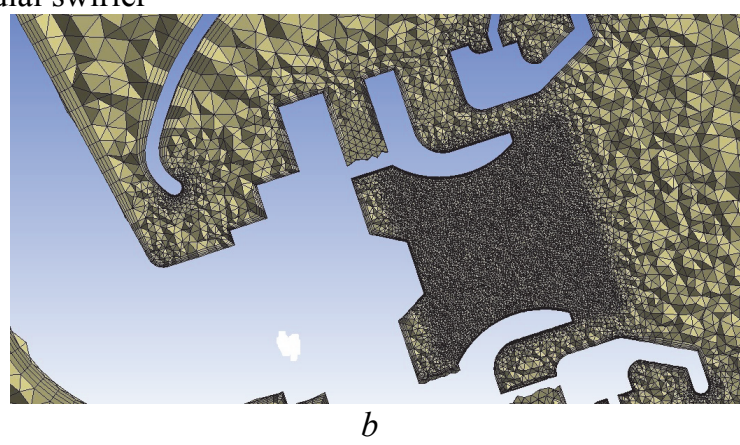

Fig. 5 - Unstructured tetrahedral meshes: $a$ - tetrahedral meshes with prismatic layers for single annular combustor; $b$ - high mesh quality with smaller element size around injection area; $c$ - high quality tetrahedral mesh for can combustor 


\section{Boundary conditions:}

In this paper, no slip and adiabatic boundary were set up for all the walls of the combustors. The pressure outlet boundary was specified at the combustor outlet. Mass flow inlet boundary was set for the fuel and air inlet. Liquid Jet A was set up for fuel with LISA and $\mathrm{TAB}$ model for primary and secondary break up modeling. The mass flow rate, temperature and pressure of air are $0.8 \mathrm{~kg} / \mathrm{s}, 650[\mathrm{~K}]$ and 9 [atm] respectively. There are 3 types of fuels sprayed from the single nozzle into the combustor, and the parameters of injection in Table 1.

Table 1.

Fuel injection data for 3 various fuel sprays

\begin{tabular}{|l|c|c|c|}
\hline \multicolumn{1}{|c|}{ Injection conditions } & Case-1 & Case-2 & Case-3 \\
\hline Pressure difference of injection [atm] & 34 & 40 & 47 \\
\hline Spray angel [deg] & 20 & 25 & 35 \\
\hline Diameter of Nozzle [mm] & 1 & 1.2 & 1.5 \\
\hline Temperature of Fuel [K] & 300 & 300 & 300 \\
\hline Mass flow rate [kg/s] & 0.023 & 0.023 & 0.023 \\
\hline Surface tension & 0.024 & 0.024 & 0.024 \\
\hline
\end{tabular}

\section{Results and discussion:}

The combustor performance was evaluated through the analysis of the temperature and NO distribution for different injection conditions.

\section{Temperature distribution with various initial fuel droplet diameters:}

Figure. 6 shows the temperature distribution inside the can combustor for the liquid fuel, in various initial droplet diameters. As seen in Figure 6, obvious differences are observed on the flame temperatures and structures respectively for the 3 various cases. The maximum flame temperature inside the combustor is obtained, which is $2128 \mathrm{~K}$ for case 3 and in this case the initial diameter of droplets are 79 microns. The maximum flame temperature in Case 2 is 2099 when the initial droplet diameter is 67 microns and for case 1 is $2096 \mathrm{~K}$ respectively in initial diameter of 52.15 microns of droplets. The maximum flame temperatures and the shape of flame inside the combustor for these 3 cases are not significant but the flame shape in case 3 is more uniform than the other cases due to vaporization process of liquid kerosene in this case it is clear that droplet vaporization process time, will decrease, when droplet diameters are minimum. In case 3 the injection pressure drop is 47 atm so the initial droplet diameters are minimum despite of fuel nozzle geometrical parameters. As it is shown in Figure. 6, due to the vaporization process of liquid droplets of fuel, a low temperature region in the central recirculation zone is obtained for the all of the cases respectively. However, due to the rapidly mixing of gas and air, the temperature in the central recirculation zone in Case 1 is higher than 2 other cases. The outlet temperature in all cases are almost $1610 \mathrm{~K}$.

\section{NO distribution (analyze emission process):}

The NO mass fraction distribution inside the can combustor for the combustion of liquid kerosene is shown in Figure 7. As seen in Fig. 7, the NO mass fraction distribution is similar to the temperature distribution inside the combustor. By obtaining the results of our simulation, it is clear that the maximum concentration of NO will obtain where, there is maximum temperature. So the maximum NO mass fraction is obtained for case 1 (1.854 ppm). The NO distribution for case 2 and 3, are almost $1.57 \mathrm{ppm}$. 

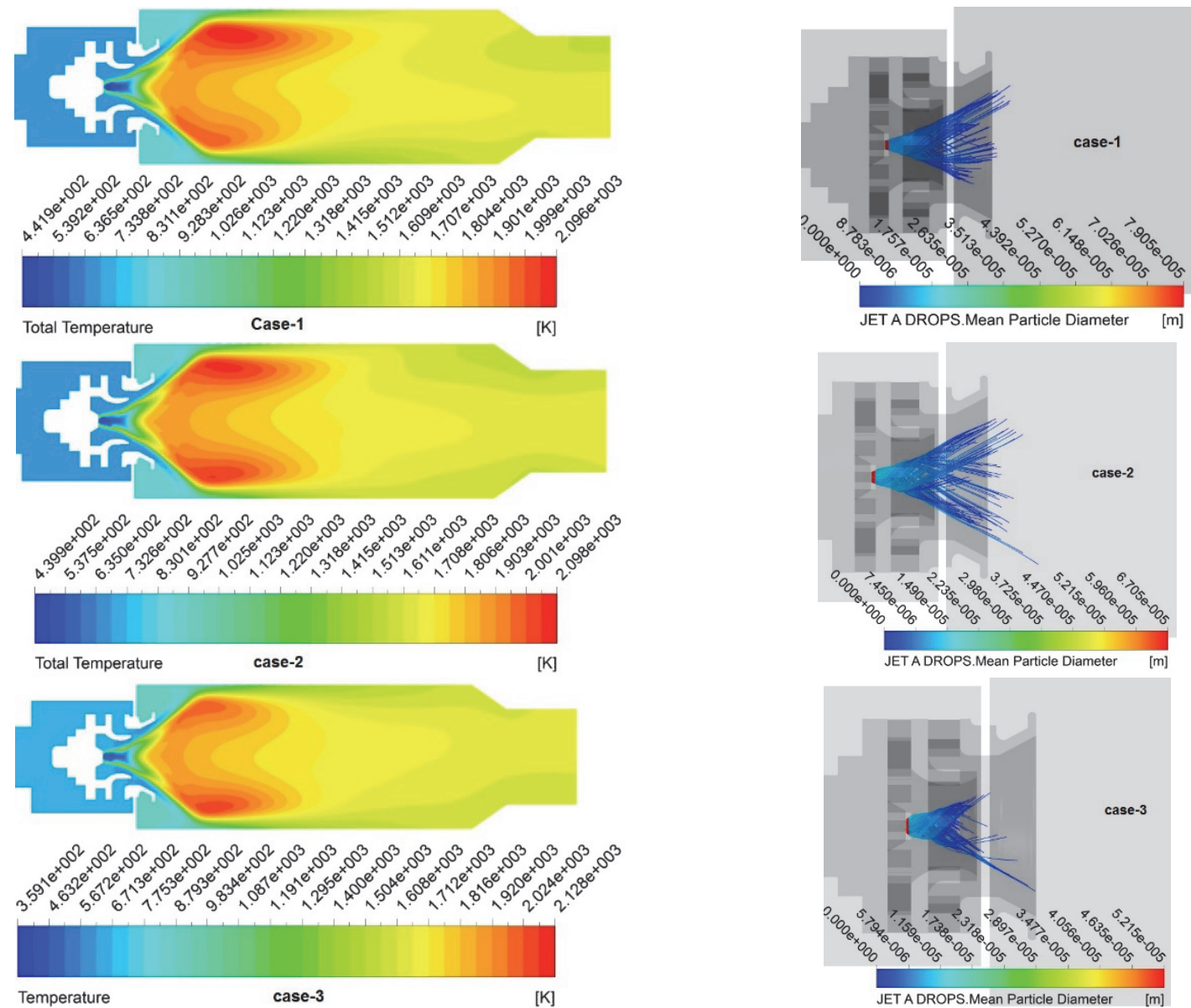

Fig. 6 - contours of temperature distribution inside the can type combustor along the XY plane and initial droplet diameters in various condition of injection

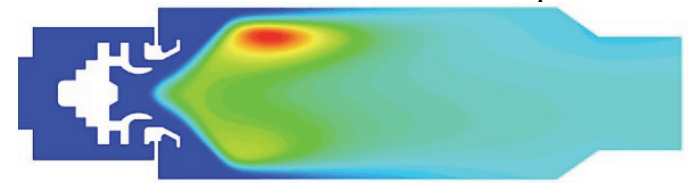

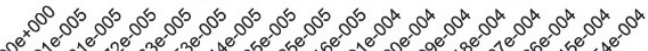

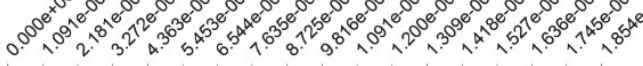

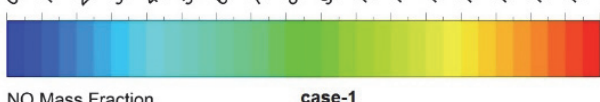

Fig. $7 a$

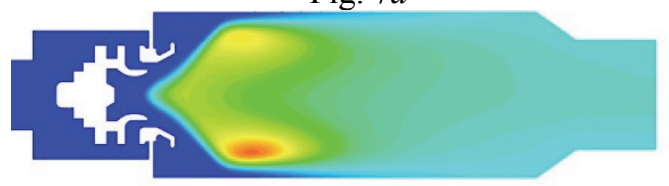

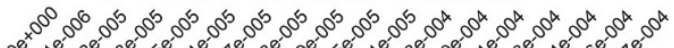

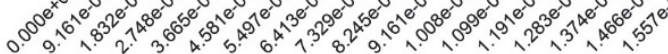

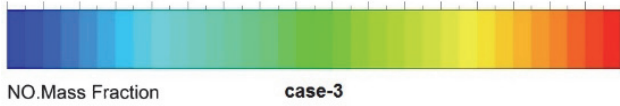

Fig. $7 c$

Fig. 7 - Contours of NO distribution inside the can type combustor along the $\mathrm{XY}$ plane in various condition of injection

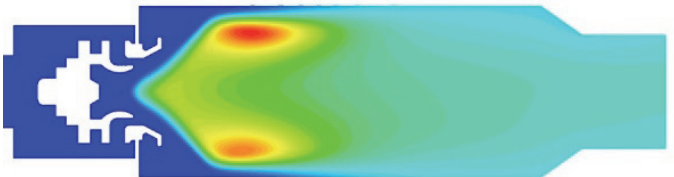

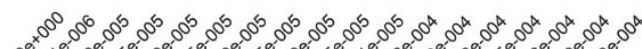

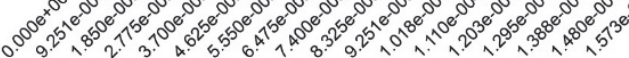

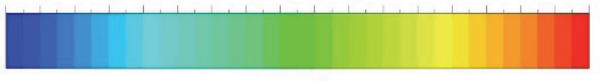

NO.Mass Fraction case-2

Fig. $7 b$

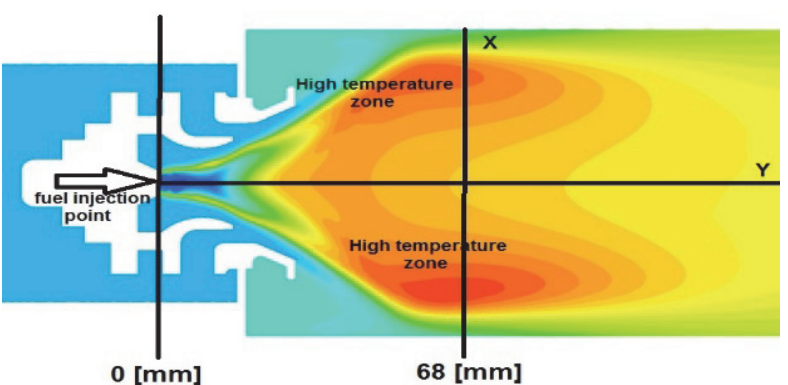

Fig. 8 - Lines with points along radial and axial distances of combustor 
The shape and distribution and concentration of NO depends on many factors such as different condition of atomization of fuel in different combustion and design of dilution holes in order to decrease the temperature inside the burner. The concentration of NO at the outlet of combustor for case 1, 2, and 3 are $0.467 \mathrm{ppm}, 0.442 \mathrm{ppm}, 0.4332 \mathrm{ppm}$.

Temperature and No distribution on diagrams

In this part of study we will show all the results above, on diagrams which shows distribution of $\mathrm{NO}$ and temperature along the $\mathrm{X}$ and $\mathrm{Y}$ system of coordinate inside the combustor. These coordinates start at the injection point of fuel atomizer to the outlet of combustor. A vertical Y coordinate $68 \mathrm{~mm}$ from injection point of fuel atomizer along the combustor (shown in figure 8) will show NO and temperature fluctuations at the radial distance of combustor. All diagrams are shown in figure 9.
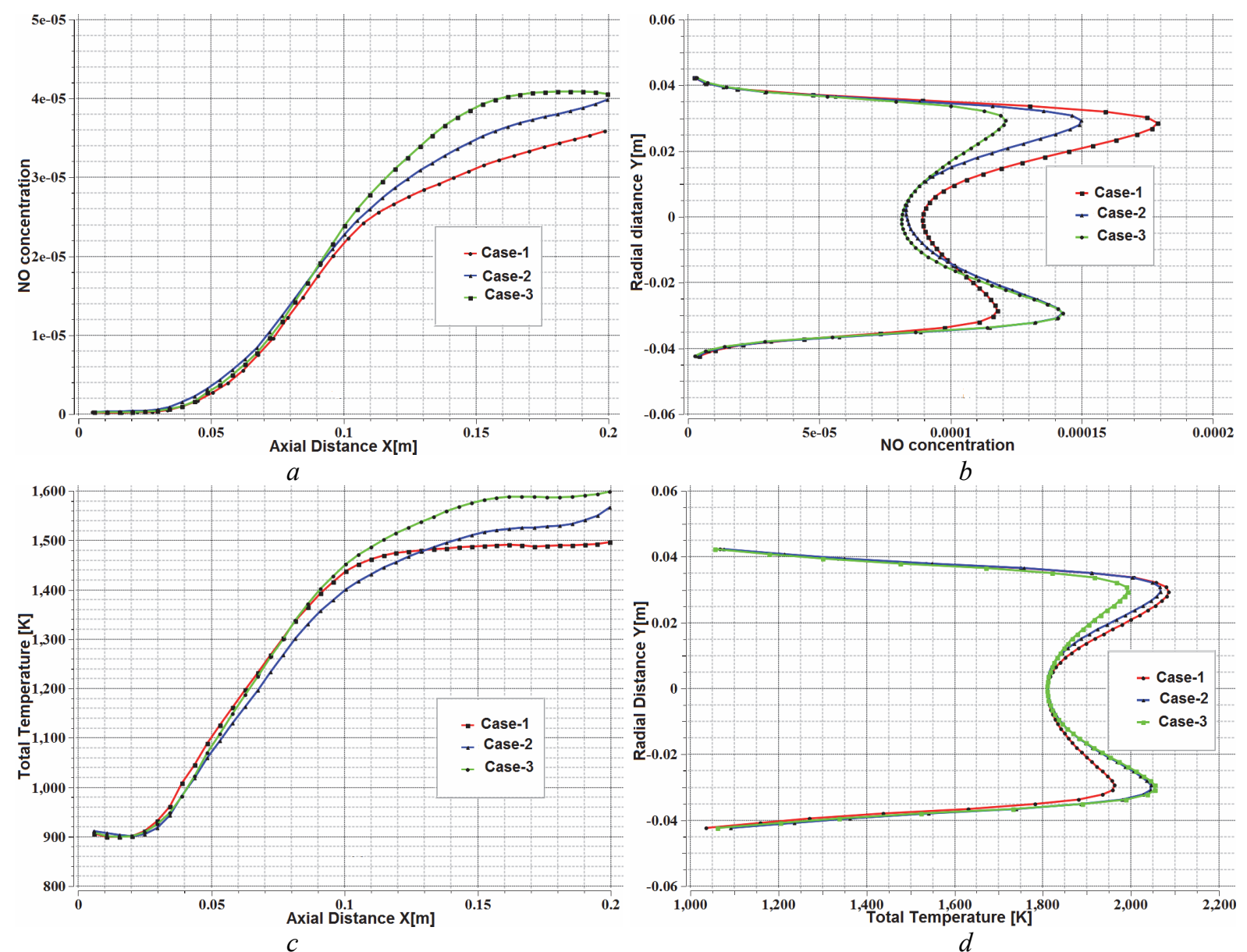

Fig. 9 -Diagrams of NO and temperature distribution:

$a-\mathrm{NO}$ distribution along the combustor; $b-\mathrm{NO}$ distribution along the radial distance;

$c$-Temperature distribution along the combustor; $d$-Temperature distribution along the radial distance

Perform the case- 3 injection characteristics on a real gas turbine combustor

In this study we selected case-3 injection data to perform on a real gas turbine combustor without any dilution holes, because of the 1-high injection pressure to have minimum of initial droplet sizes.2-shorter vaporization time of droplets.3-uniform distribution of temperature along and inside the combustor. The behave of droplets and its sizes and time of vaporization are shown in figure 10. The $\mathrm{NO}$ and temperature distribution in this simulation are shown in figure 11. 

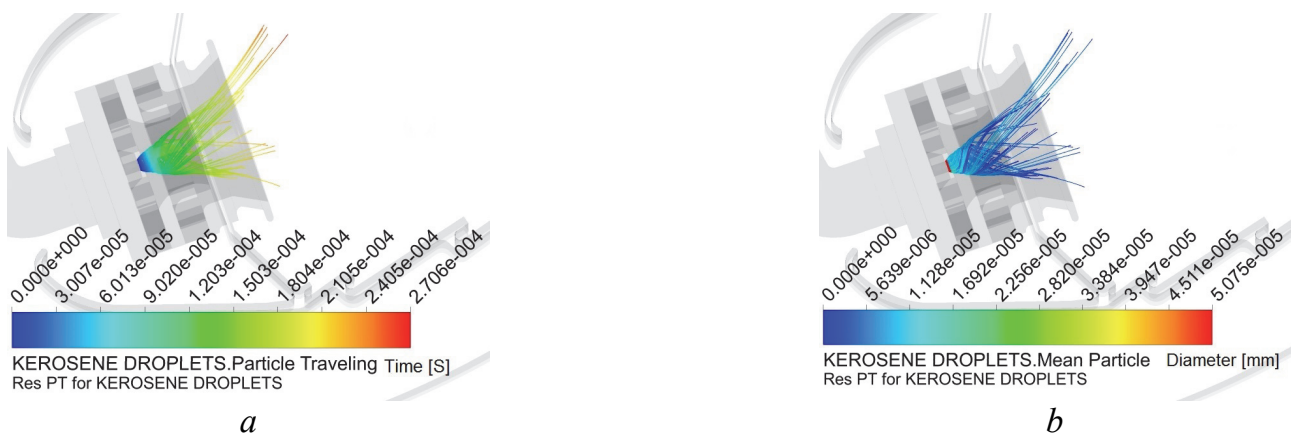

Fig. 10 - Droplet characteristics:
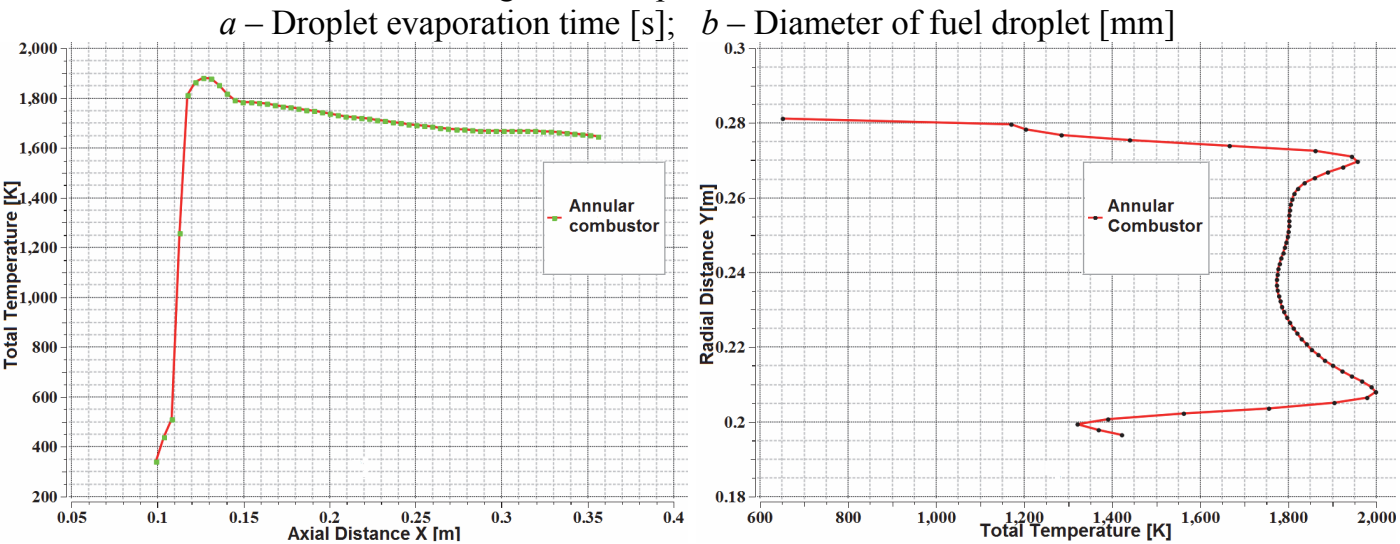

$a$
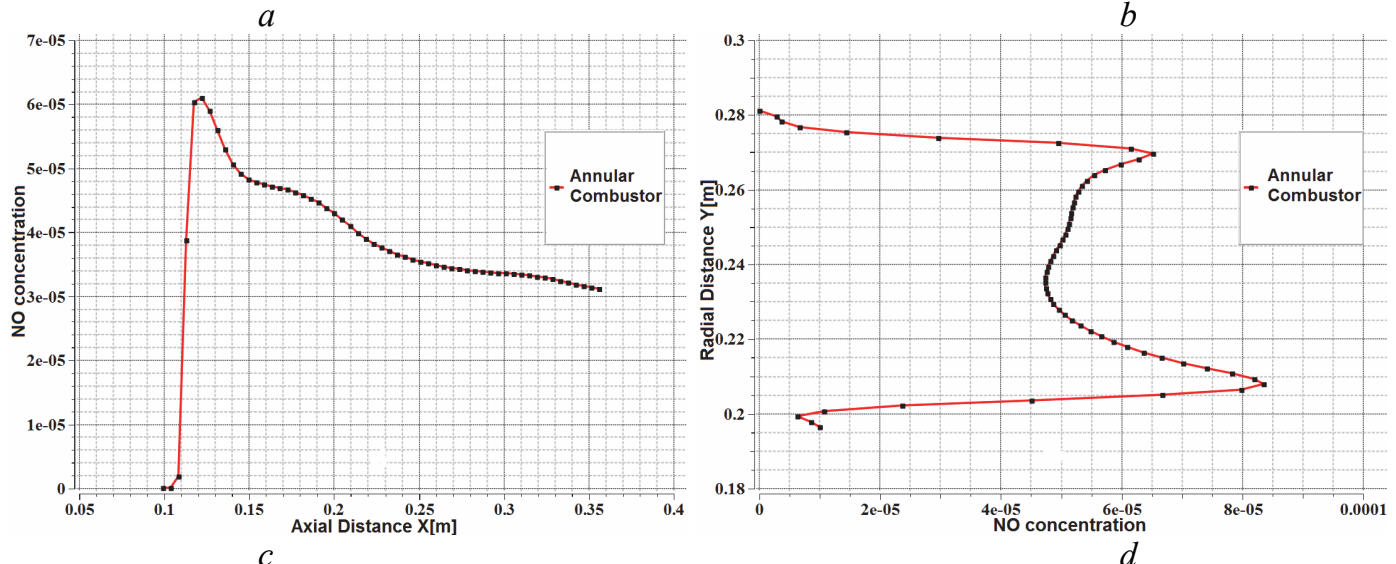

Fig. 11 - Diagrams of NO and temperature distribution: $a$ - temperature along the combustor; $b$ - temperature along the radial distance; $c-\mathrm{NO}$ along the combustor; $d-\mathrm{NO}$ along the radial distance
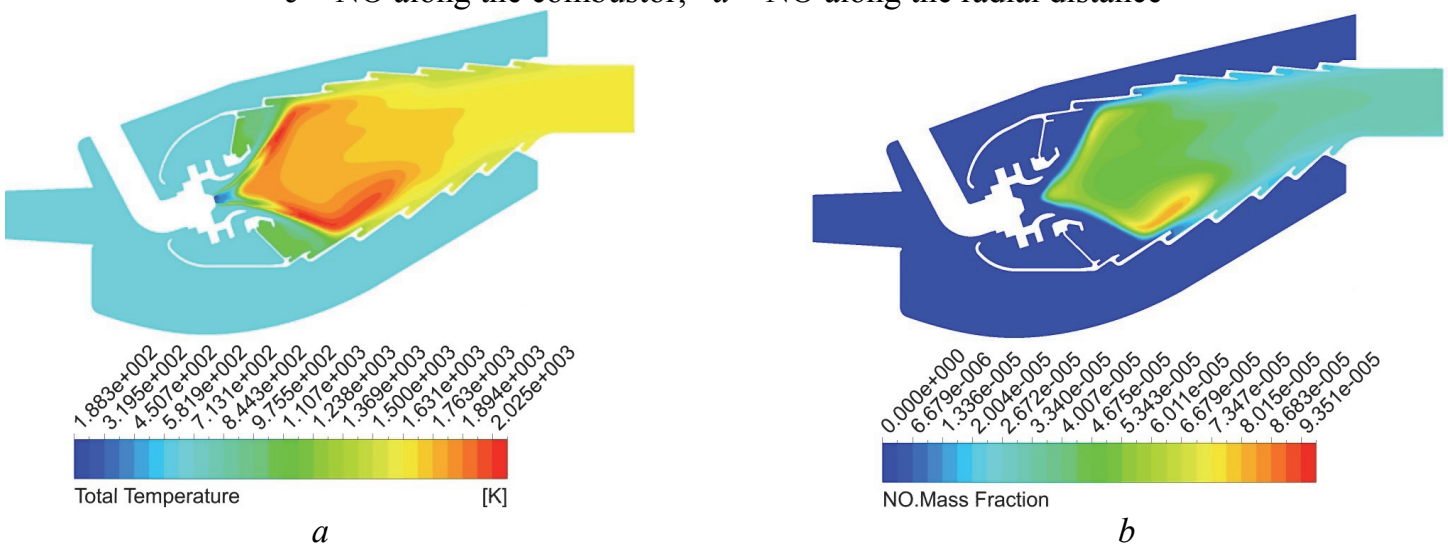

Fig. 12 -Contours of temperature and NO distribution: $a$ - temperature distribution along the combustor; $b$-Concentration of NO and its distribution 
In figure 10 it is clear that the initial droplet size in 47 atm of pressure drop of injection, in fuel atomizer, is almost 50 microns, in fact comparing with case 3 there is not a significant different and the maximum time of evaporation of droplets is $0.00027 \mathrm{~s}$.

In figure $12 \mathrm{NO}$ and temperature distribution contours are shown in this type of annular combustor without any primary and secondary or dilution holes.

The maximum temperature is $2025 \mathrm{~K}$ and the shape and structure of flame depends on injection conditions .the outlet temperature and NO is $1613 \mathrm{~K}$ and $2.874 \mathrm{ppm}$ which it has not a significant difference with our simulation in 3 cases. The maximum concentration of NO is $9.351 \mathrm{ppm}$ where have a high temperature, which is higher than 3 numerical cases in this paper because our shape and geometrical parameter and sizes in this case, is absolutely different from the can type of combustor, and the volume of our annular combustor is more that the can type in this investigation, so there will be not adequate air for cooling the area of combustion with high temperature which has a high temperature regions.

To reduce the level of NO emission we should design the primary and secondary dilution holes for cooling the high temperature areas in our burner means the liner in this case.

Beside that the form and shape of fuel spray play a very important role to create and provide minimum fuel droplets with high efficiency of injection.

\section{Conclusion}

Numerical simulation was carried out in this study to investigate the liquid combustion performance and emissions for the can and annular type of combustors in 3 various cases and a single case for annular combustor.

All the simulation in this paper were performed with ANSYS CFX 15 with a detailed chemistry in PDF flamelet model of combustion and the flame temperature and species concentration distributions inside the combustor were obtained. The results of simulation showed that the appropriate case for our annular combustor simulation, is case 3 which the spray angel was 35 degree with a $1.5 \mathrm{~mm}$ diameter of nozzle and $47 \mathrm{~atm}$ for pressure difference of injection. The results in this case showed that in a high pressure difference in our pressure swirled atomizer, we reached the minimum fuel droplet diameter of 50 microns, with a minimum time of droplet evaporation.

This investigation was a parametric simulation of combustion of liquid kerosene which means that, first of all the simulation were performed in a simple can type combustor to understanding the problem and select one of them, which has a good results to perform on a real gas turbine combustion chamber.

All of the outlet temperature in this simulation were almost $1610 \mathrm{~K}$ but the structure and shape of the flames were different because of injection various initial conditions: 1 injection pressure difference 2 - spray angel 3 - diameter of fuel nozzle 4 - the method of primary and secondary breakup of liquid fuel.

Literature: 1. Clayton, T. C. Multiphase handbook [Text] / T. C. Clayton. - USA, 2006. - 1128 p. 2. Lefebvre, A. H. Combustion alternative fuel and emissions [Text] / A. H. Lefebvre, R. B. Dilip. - London, New York : CRC Press-Taylor\&Francis Group. -560 p. 3. Gang, P. Combustion of reformed gas and liquid fuel in CRGT combustor [Text] / P. Gang, Z. Hongtao // Izgaranje poboljšanog plina i tekućeg goriva u CRGT komori izgaranja. - P. 715-722. - ISSN 1330-3651 (Print), ISSN 1848-6339 (Online) UDC / UDK 621.438.057:519.876.5. 4. Jeongkuk, Y. A Basic Study of the Behavior Characteristics of Gas- and Liquid- phase Fuel Spray [Text] / Y. Jeongkuk, K. Mincheol // Proceedings of the 6th WSEAS International Conference on FLUID MECHANICS (FLUIDS'09). — P. 80-85. - ISSN 1790-5095. - ISBN: 978-960-474-40-6. 5. Man, C. F. External characteristics spray atomization from a nasal spray device [Text] / C. F. Man, K. Inthavong, Y. William // Seventh International Conference on CFD in the Minerals and Process Industries CSIRO. Melbourne, Australia 9-11 December 2009. - P. 1-6. 6. ANSYS CFX-Solver Theory Guide. ANSYS CFX 
Release 15.0 [Электронный ресурс] / ANSYS, Inc. // Southpointe 275 Technology Drive. - Canonsburg : PA 15317, 2015. - 352 p. - 1 CD-ROM. 7. Warnatz, J. Combustion Physical and Chemical Fundamentals, Modeling and Simulation, experiments, Pollutant Formation [Text] / J. Warnatz, M. U. Dibble. - Berlin : Springer, 2001. 8. Paterson, P. M. Combustion of kerosene in counter-Flow Diffusion Flames [Text] / P. M Paterson, A. G. Kyne, M. Pourkashian // AIAA Journal of Population and Power. - 2001. - 17(2) - P. 453460. 9. Peters, $N$. Laminar Diffusion Flamelet Models in Non Premixed turbulent combustion [Text] / N. Peters // Prog. Energy Comb. Sci. - 1984. - P. 319-339. 10. Hashemi, S. A. Investigation of the effect of air turbulence intensity on NOx emission in non-premixed hydrogen and hydrogen-hydrocarbon composite fuel combustion [Text] / S. A. Hashemi, A. Fattahi, G. Sheikhzadeh // International Journal of Hydrogen Energy. - 2011. - 36. P. 10159-10168.

Bibliography (transliterated): 1. Clayton, T. C. Multiphase handbook. USA, 2006. Print. 2. Lefebvre, A. H, and R. B. Dilip. Combustion alternative fuel and emissions. London, New York : CRC Press-Taylor\&Francis Group. Print. 3. Gang, P., and Z. Hongtao. "Combustion of reformed gas and liquid fuel in CRGT combustor." Izgaranje poboljšanog plina i tekućeg goriva u CRGT komori izgaranja. 715-722. ISSN 1330-3651 (Print), ISSN 1848-6339 (Online) UDC / UDK 621.438.057:519.876.5. Print. 4. Jeongkuk, Y., and K. Mincheol. "A Basic Study of the Behavior Characteristics of Gas- and Liquid- phase Fuel Spray." Proceedings of the 6th WSEAS International Conference on FLUID MECHANICS (FLUIDS'09). 80-85. ISSN 1790-5095. ISBN: 978960-474-40-6. Print. 5. Man, C. F., K. Inthavong and Y. William. "External characteristics spray atomization from a nasal spray device." Seventh International Conference on CFD in the Minerals and Process Industries CSIRO. Melbourne, Australia 9-11 December 2009. 1-6. Print. 6. ANSYS, Inc. "ANSYS CFX-Solver Theory Guide. ANSYS CFX Release 15.0." Southpointe 275 Technology Drive. Canonsburg : PA 15317, 2015. 1 CDROM. 7. Warnatz, J., and M. U. Dibble. Combustion Physical and Chemical Fundamentals, Modeling and Simulation, experiments, Pollutant Formation. Berlin : Springer, 2001. Print. 8. Paterson, P. M., A. G. Kyne and M. Pourkashian. "Combustion of kerosene in counter-Flow Diffusion Flames." AIAA Journal of Population and Power 17(2) (2001): 453-460. Print. 9. Peters, N. "Laminar Diffusion Flamelet Models in Non Premixed turbulent combustion." Prog. Energy Comb. Sci. 1984. 319-339. Print. 10. Hashemi, S. A., A. Fattahi and G. Sheikhzadeh. "Investigation of the effect of air turbulence intensity on NOx emission in non-premixed hydrogen and hydrogen-hydrocarbon composite fuel combustion". International Journal of Hydrogen Energy 36 2011. 10159-10168.

Received to editorial board 16.02.15 